\title{
A New Emerging Role of Clinical Pharmacist in Radiology Department- Reporting Errors and Clinical Intervention by Clinical Pharmacist
}

\author{
Varshitha N*, Sai Arvind D and Ramesh G \\ Department of Pharmacy, Vigan Pharmacy College, Guntur, India
}

\begin{abstract}
Radiology department will provide a variety of inpatient and outpatient services. These services use medical imaging such as radiography, computed tomography, magnetic resonance imaging, nuclear medicine, positron emission tomography, and ultrasound. Error in radiology department implies an incorrect interpretation of an imaging study. To improve safety, error-reporting strategies should include identifying errors, admitting mistakes, correcting unsafe conditions, and reporting systems improvements to stakeholders. Reducing errors will improve patient care, may reduce costs and will improve the image of the hospital. To identify reporting errors in CT, MRI and $\mathrm{x}$ ray in a tertiary care hospital and assess the role of clinical pharmacist in reducing the reporting errors. In this study patients who were referred to undergo CT scan, MRI and x ray were taken in to the study. Duration of study was 8 months. Patients reports were taken and reporting errors were noted in the respective data collection form reporting errors was identified and analyzed. In the present study very less error reports were identified which shows the regular monitoring of the clinical pharmacist, results in the accurate diagnosis of the patient and accurate treatment plan that reflects the health care practice in a hospital. Error in reports can cause wrong diagnosis and which may result in false treatment plan. So identification of errors in reports by the health care professional (pharmacist) at the basic level before going for final assessment of the condition may improve patient care, reduce healthcare cost and time for re do's. This also creates a new task for the clinical pharmacist.
\end{abstract}

Keywords: Computed tomography; Magnetic resonance imaging; Nuclear medicine and ultrasound

\section{INTRODUCTION}

Radiology department will provide a variety of inpatient and outpatient services. These services use medical imaging, such as radiography, Computed Tomography (CT), Magnetic Resonance Imaging (MRI), nuclear medicine, positron emission tomography, and ultrasound. A clinician referring a patient for a radiological investigation is generally looking for a number of things in the ensuing radiologist's report: accuracy and completeness of identification of relevant findings, a coherent opinion regarding the underlying. Error in radiology department implies an incorrect interpretation of an imaging study, many errors are of little or no significance to the patient and some significant errors remain undiscovered [1]. When viewing radiologic studies, there is a tendency to become "satisfied" after identifying the first abnormality that leads to a failure to search for additional findings [2]. If diagnostic quality was not satisfied the value of the radiographic images decreases and it should be repeated, resulting in increased exposure to radiation, more costs and waste of time [3]. Most of the errors consisting of either missed findings or "overcalled" pathology. About $75 \%$ of malpractice cases against radiologists are due to diagnostic errors [4].

Radiologist specific Causes of errors were classified:

(a) Complacency - the finding was appreciated but attributed to the wrong cause

(b) Faulty reasoning - the finding was appreciated and interpreted as abnormal, but attributed to the wrong cause

(c) Lack of knowledge on the part of the viewer

(d) Under reading - finding missed

(e) Poor communication - lesion identified and interpreted correctly, but the message fails to reach clinician

(f) Miscellaneous - lesion not present on the images, even in retrospect. This may be due to limitations of the examination or an inadequate examination.

(g) Complications - most frequently during invasive procedures

Correspondence to: Varshitaha N, Vigan Pharmacy College, Guntur, India, E-mail: aravindpharmd@yahoo.com

Received: Janaury 07, 2019, Accepted: February 04, 2019, Published: February 17, 2019

Citation: Varshitha N, Sai Arvind D, Ramesh G (2019) A New Emerging Role of Clinical Pharmacist in Radiology Department- Reporting Errors and Clinical Intervention by Clinical Pharmacist. J Biomol Res Ther, 8: 173. doi: 10.35248/2167-7956.19.8.173

Copyright: (C) 2019 Varshitha N, et al. This is an open access article distributed under the term of the Creative Commons Attribution License, which permits unrestricted use, distribution, and reproduction in any medium, provided the original work is properly cited. 
Moreover, there are system issues contributing to errors. System contributors to discrepancies and errors include the following:

(a) Staff shortages

(b) Excess workload - studies have demonstrated degradation of lung cancer detection with decreased viewing time, and increased error rates in abdominal CT reporting when the radiologist reports more than 20 studies per day

(c) Inexperience of staff

(d) Inadequate equipment

(e) Inadequacy of clinical information available to the reporting radiologist - the clinical diagnosis has been shown to change in $50 \%$ of cases following communication between clinician and radiologist, with a change of treatment in $60 \%$ of cases discussed. This is one of the many strong arguments against the use of remote tele radiology reporting for radiologic studies. Knowledge of pertinent clinical history has been shown to increase the accuracy of CXR interpretations from 16 to $72 \%$ for trainees, and from 38 to $84 \%$ for consultant-grade radiologists.

(f) Inappropriate expectations of the capability of a particular radiologic technique, which might not be suitable for the question being asked of it.

(g) Unavailability of previous studies or reports for comparison

(h) Over reliance on locum radiologist within a department

The level of error varies depending on the radiological investigation, but the range is $2-20 \%$ for clinically significant or major error [5]. The main reason for studying medical errors is to try to prevent them. Clinical pharmacist generally involves in counseling the patients, checking drug interactions, prescription audit, running drug information center, pharmacovigilance. Clinical pharmacist being responsible healthcare professionals can also play an important role in reporting errors in radiology department. To improve safety, error-reporting strategies should include identifying errors, admitting mistakes, correcting unsafe conditions and reporting systems improvements to stakeholders [6]. Reducing errors will improve patient care, may reduce costs and will improve the image of the hospital [7].

\section{Objectives}

The current study aims to identify the numbers of reporting errors in CT scan, MRI and x-ray in a tertiary care hospital of south India and assess the role of clinical pharmacist in identification and clinical intervention of radiological error $[8,9]$.

\section{Patients and Methods}

It is an observational cross sectional study conducted for a period of 8 months in a tertiary care hospital of south India. In this study patients who were referred to undergo CT scan, MRI and $\mathrm{x}$ ray were taken in to the study. Patients reports were taken and reporting errors were noted in the respective data collection form i.e. CT scan, MRI and x ray. Reporting errors were identified and collected data was analyzed by using SPSS software $[10,11]$.

\section{Results and Discussions}

\section{CT scan}

From Dec 2017- July 2018 a total of 2139 scanning reports were collected and in that 6 errors were reported which is equal to 2.8 per 1000 (Table 1). From December 2016 to July 2017 a total of 2139 CT scans were performed among them 6 reporting errors were found (Graph 1).

\section{MRI Scan}

From Dec 2017- July 2018 a total of 2005 scanning reports were collected and in that 4 errors were reported which is equal to 1.99 per 1000 (Table 2). From December 2016 to July 2017 a total of 2005 MRI were performed among them 6 reporting errors were identified (Graph 2).

\section{Rays}

From Dec 2017- July 2018 a total of 15298 scanning reports were collected and no errors were reported Table 3 and Graph 3.

Table 1: From December 2016 to July 2017 a total of 2139 CT scans were performed among them 6 reporting errors were found.

\begin{tabular}{cccc}
\hline Month & Total CT & No of Reporting Errors & Per 1000 \\
\hline Dec 2016 & 190 & 3 & 15.7 \\
\hline Jan 2017 & 224 & 1 & 4.46 \\
\hline Feb 2017 & 231 & 0 & 0 \\
\hline Mar 2017 & 257 & 0 & 0 \\
\hline Apr 2017 & 274 & 0 & 0 \\
\hline May 2017 & 288 & 0 & 0 \\
\hline June 2017 & 334 & 2 & 5.98 \\
\hline July 2017 & 341 & 0 & 0 \\
\hline
\end{tabular}

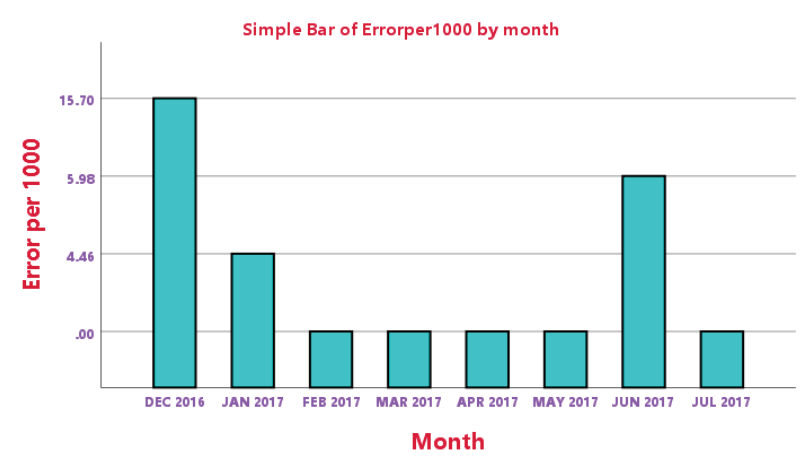

Graph 1: Graphical representation showing reporting errors in CT scan from December 2016-july 2017.

Table 2: From December 2016 to July 2017 a total of 2005 MRI were performed among them 6 reporting errors were identified.

\begin{tabular}{cccc}
\hline Month & Total MRI & No of Reporting Errors & Per 1000 \\
\hline Dec 2016 & 212 & 1 & 4.71 \\
\hline Jan 2017 & 240 & 2 & 8.33 \\
\hline Feb 2017 & 226 & 1 & 4.42 \\
\hline Mar 2017 & 284 & 0 & 0 \\
\hline Apr 2017 & 228 & 0 & 0 \\
\hline May 2017 & 252 & 0 & 0 \\
\hline June 2017 & 271 & 1 & 3.69 \\
\hline July 2017 & 292 & 1 & 3.42 \\
\hline
\end{tabular}




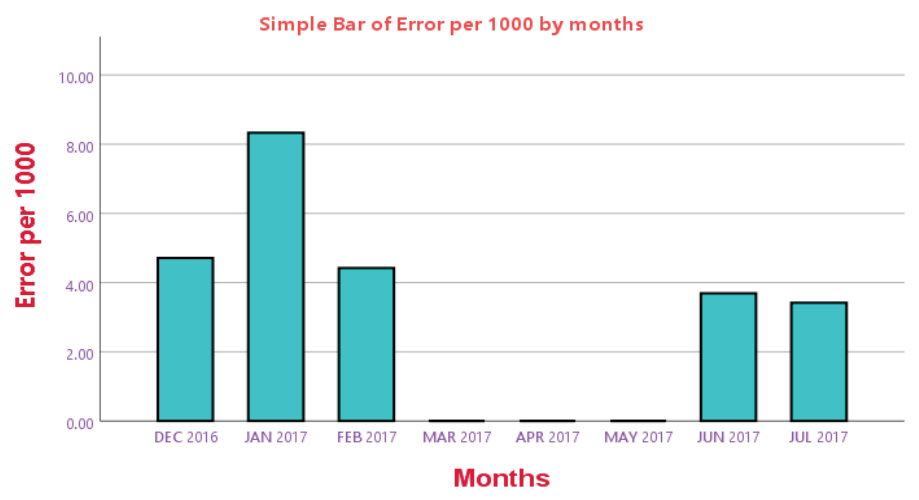

Graph 2: Graphical representation showing reporting errors in MRI scan from December 2016-july 2017.

Table 3: From December 2016 to July 2017 a total of 15298 X-rays were performed and there was zero reporting errors.

\begin{tabular}{cccr}
\hline Month & Total X-Ray & No of Reporting Errors & Per 10000 \\
\hline Dec 2016 & 1466 & 0 & 0 \\
\hline Jan 2017 & 1937 & 0 & 0 \\
\hline Feb 2017 & 1812 & 0 & 0 \\
\hline Mar 2017 & 2140 & 0 & 0 \\
\hline Apr 2017 & 1717 & 0 & 0 \\
\hline May 2017 & 2417 & 0 & 0 \\
\hline June 2017 & 1669 & 0 & 0 \\
\hline July 2017 & 2140 & 0 & 0 \\
\hline
\end{tabular}

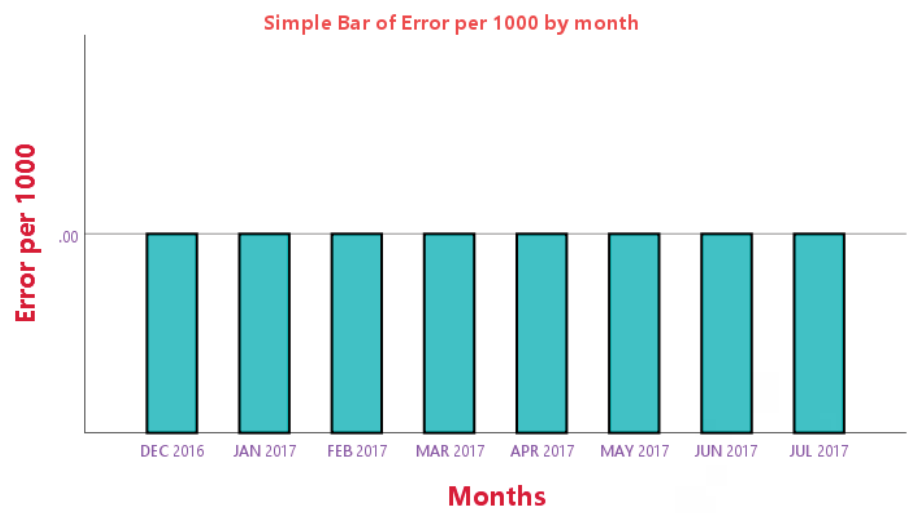

Graph 3: Graphical representation showing reporting errors in $\mathrm{x}$ ray from December 2016-july 2017.

\section{Conclusion}

Reports are main criteria in diagnosing the patient condition from which the entire treatment plan will be designed for the patient. Error in reports can cause wrong diagnosis and which may result in false treatment plan. So identification of errors in reports by the health care professional (pharmacist) at the basic level before going for final assessment of the condition may improve patient care, reduce healthcare cost and time for re do's. This also creates a new task for the clinical pharmacist. In the present study very less error reports were identified which shows the regular monitoring of the clinical pharmacist, results in the accurate diagnosis of the patient and accurate treatment plan that reflects the health care practice in a hospital.

\section{REFERENCES}

1. https://collections.nlm.nih.gov/master/borndig/101563471/ Medication\%20errors\%20 occurring\%20 in \%20 the \% 20 radiologic\%20services\%20department.pdf

2. Berlin L. Radiologic errors, past, present and future. J Diagnosis. 2014;1:79-84.

3. Salemi F, Shokri A, Falah-Kooshki S. Common Errors on Conventional and Digital Panoramic Radiographs. Avicenna J Den Res. 2014;6:25-34.

4. https://www.appliedradiology.com/articles/toward-decreasingdiagnostic-errors

5. Wolf JR, Hughes RG. Error Reporting and Disclosure. Pati Saf \& Qual. 2008;35:20-26.

6. Goddard P, Leslie A, Jones A, Wakeley C, Kabala J. Error in Radiology. British J Rad. 2011;74:949-951.

7. http://www.kipsq.org/Portals/26/Newsletters/Navigator/2017/ PSONav0517.pdf

8. Driscoll DO, Halpenny D, Guiney M. Radiological error-an early assessment of departmental radiology discrepancy meetings. Ir Med J. 2012;105:172-174.

9. Brady AP. Error and discrepancy in radiology: inevitable or avoidable. J Insights Imag. 2017;8:171-182.

10. https://www.radiologie24.ch/RAD\%20MEDIATHEK/7b-newsradiologie-qm/2012-jmiro-diagnostic-radiology-errors.pdf

11. Bruno MA. Understanding and Confronting Our Mistakes: The Epidemiology of Error in Radiology and Strategies for Error Reduction. Radio-graphics. 2015;35:1668-1676. 